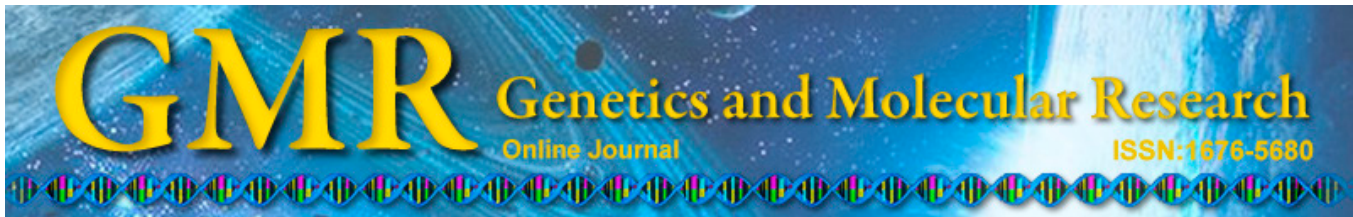

\title{
Genetic diversity of popcorn genotypes using molecular analysis
}

\author{
F.S. Resh ${ }^{1}$, C.A. Scapim ${ }^{2}$, C.A. Mangolin ${ }^{3}$, M.F.P.S. Machado ${ }^{3}$, \\ A.T. do Amaral Jr. ${ }^{4}$, H.C.C. Ramos $^{4}$ and M. Vivas ${ }^{4}$ \\ ${ }^{1}$ Programa de Pós-Graduação em Genética e Melhoramento, \\ Universidade Estadual de Maringá, Maringá, PR, Brasil \\ ${ }^{2}$ Departamento de Agronomia, Universidade Estadual de Maringá, \\ Maringá, PR, Brasil \\ ${ }^{3}$ Departamento de Biotecnologia, Genética e Biologia Celular, \\ Universidade Estadual de Maringá, Maringá, PR, Brasil \\ ${ }^{4}$ Laboratório de Melhoramento Genético Vegetal, \\ Universidade Estadual do Norte Fluminense Darcy Ribeiro, \\ Campos dos Goytacazes, RJ, Brasil \\ Corresponding author: A.T. do Amaral Jr. \\ E-mail: amaraljr@pq.cnpq.br \\ Genet. Mol. Res. 14 (3): 9829-9840 (2015) \\ Received December 14, 2014 \\ Accepted June 6, 2015 \\ Published August 19, 2015 \\ DOI http://dx.doi.org/10.4238/2015.August.19.16
}

ABSTRACT. In this study, we analyzed dominant molecular markers
to estimate the genetic divergence of 26 popcorn genotypes and evaluate
whether using various dissimilarity coefficients with these dominant
markers influences the results of cluster analysis. Fifteen random
amplification of polymorphic DNA primers produced 157 amplified
fragments, of which 65 were monomorphic and 92 were polymorphic.
To calculate the genetic distances among the 26 genotypes, the
complements of the Jaccard, Dice, and Rogers and Tanimoto similarity
coefficients were used. A matrix of $\mathrm{D}_{\mathrm{ij}}$ values (dissimilarity matrix) was
constructed, from which the genetic distances among genotypes were
represented in a more simplified manner as a dendrogram generated
using the unweighted pair-group method with arithmetic average. 
Clusters determined by molecular analysis generally did not group material from the same parental origin together. The largest genetic distance was between varieties 17 (UNB-2) and 18 (PA-091). In the identification of genotypes with the smallest genetic distance, the 3 coefficients showed no agreement. The 3 dissimilarity coefficients showed no major differences among their grouping patterns because agreement in determining the genotypes with large, medium, and small genetic distances was high. The largest genetic distances were observed for the Rogers and Tanimoto dissimilarity coefficient (0.74), followed by the Jaccard coefficient (0.65) and the Dice coefficient (0.48). The 3 coefficients showed similar estimations for the cophenetic correlation coefficient. Correlations among the matrices generated using the 3 coefficients were positive and had high magnitudes, reflecting strong agreement among the results obtained using the 3 evaluated dissimilarity coefficients.

Key words: Genetic diversity; Random amplification of polymorphic DNA; Zea mays

\section{INTRODUCTION}

Brazil is one of the major producers of corn worldwide, and according to Bordallo et al. (2005), enormous potential exists for the production of specialty corns such as popcorn. Although popcorn is very popular in Brazil, its production and marketing have been understudied, and there is little official information regarding planting areas, production amounts, and import quantities (Galvão et al., 2000; Pereira and do Amaral Jr., 2001; Ribeiro et al., 2012; Pena et al., 2012; Vittorazzi et al., 2013), particularly for domestic varieties in the improvement phase (Pipolo et al., 2002).

The national popcorn market remains dependent on the importation of both seed and grain because of the small number of breeding programs for this crop in Brazil (Sawazaki, 2001; Rangel et al., 2008; Freitas Jr. et al., 2009; Vittorazzi et al., 2013). Santos et al. (2012) and Silva et al. (2013) described the shortage of registered cultivars with the Brazilian Ministry of Agriculture, Livestock and Supply (Ministério da Agricultura, Pecuária e Abastecimento) that combine good agronomic characteristics with high scalability for producers. According to Scapim et al. (2002), the small number of cultivars limits the expansion of popcorn cultivation in Brazil, as packaging companies will not work with local popcorn because of its limited supply in the marketplace, which is attributed to the lack of seed availability. To improve popcorn, several factors related to popcorn quality, including texture and softness, as well as yield and agronomic characteristics, should be taken into account. Farmers are most interested in high yields, whereas consumers are interested in popping expansion, which gives the popcorn a better and softer texture.

According to Hallauer et al. (2010), corn breeding and popcorn improvement have common goals in that both are focused on selecting populations of interest. Populations with high potential for use as progenitors in intrapopulation selection programs should have high means and high genetic variability regarding characteristics of interest. For improvement, molecular markers that provide a reliable measure of genetic diversity are used to determine 
the degrees of relatedness among lines and varieties and are also used to protect intellectual property rights, among other uses. Similarly, molecular markers can be linked to alleles of interest, helping to increase the understanding of the biology and structure of numerous characteristics, particularly quantitative characteristics (Borém and Miranda, 2013). Currently, in breeding programs for various crops, molecular markers are used to guidecrop improvements (Sakiyama et al., 2014).

Several studies have used molecular markers as tools at various stages of plant breeding programs. Moeller and Schaal (1999) used random amplification of polymorphic DNA (RAPD) marker analysis to identify genetic variation among 15 accessions of corn native to the Americas and reported high levels of polymorphism among the genetic material analyzed. These results revealed a strong correlation between the genetic relatedness and the geographical location of accessions native to the Americas. The same authors concluded that RAPD can be used to increase the understanding of intraspecific genetic differentiation. Lanza et al. (1997) indicated that RAPD is an important tool for determining the extent of variability among corn lines and for grouping various genotypes into distinct heterotic groups. Carvalho et al. (2004) analyzed 81 corn accessions and found that RAPD is a suitable marker analysis method for establishing germplasm collections. For this analysis, DNA amplification is based on the use of a single small primer that anneals to random genomic regions, and the DNA is amplified by polymerase chain reaction (Welsh and McClelland, 1990; Williams et al., 1990). Thus, RAPD markers are frequently used to evaluate genetic diversity among corn genotypes (Thormann et al., 1994; Lanza et al., 1997, Moeller and Schaal, 1999, Carvalho et al., 2004; Vilela et al., 2008; Munhoz et al., 2009; Leal et al., 2010; Souza et al., 2012).

The aim of the present study was to compare the results obtained using 3 dissimilarity coefficients to quantify genetic distance based on binary molecular data from RAPD molecular marker analysis. In addition, genetic diversity among 26 popcorn genotypes was estimated.

\section{MATERIAL AND METHODS}

\section{Genotypes analyzed}

In the present study, 26 varieties of popcorn were analyzed, including 4 hybrids (Jade, Zélia, IAC-112, and IAC-125), a genotype with an unknown pedigree (Chile), and 21 openpollinated varieties (BRS-Angela, Composto V1, Composto V2, Iguatemi 1, Iguatemi 2, Composto Barreto, Composto Matheus, P1 sintético, Composto Fracaro, Composto Aelton, PR023, IAC-112 F2, Argentina, UNB-2, PA-091, Viçosa, CMS-42, SE-013, Laranjeiras do Sul, UEM-M2, and RS-20). The pedigree of each variety is shown in Table 1.

For DNA extraction, leaves were collected in bulk from 78 plants of each of the 26 cultivars at approximately 15 days after germination. Genomic DNA was isolated following the method described by Hoisington et al. (1994). Genomic DNA was quantified using gel electrophoresis on a $0.8 \%$ agarose gel. DNA extracted from each sample was compared to DNA standards (phage $\lambda$ ) of known concentrations (50, 100, and $150 \mathrm{ng}$ ). After electrophoresis, the gel was stained in $0.5 \mu \mathrm{g} / \mathrm{mL}$ ethidium bromide and imaged on a High-Performance Ultraviolet Transilluminator (EDAS 290; UVP, LLC, Upland, CA, USA) using the program Kodak 1D 3.5 (Rochester, NY, USA). 
Table 1. Genealogy of popcorn maize genotypes evaluated in this study.

\begin{tabular}{|c|c|}
\hline Genotypes & Genealogy \\
\hline Jade & Three-way hybrid obtained from temperate and tropical germplasm \\
\hline Zélia & Three-way hybrid obtained from temperate and tropical germplasm \\
\hline IAC-112 & Simple hybrid-variety SAM with inbred lines originated from hybrid intervarietal Guarani and Yellow Viçosa \\
\hline IAC- -125 & Topcross hybrid from the Agronomic Institute of Campinas (Instituto Agronômico de Campinas - IAC) \\
\hline Chile & Material unknown genealogy \\
\hline Composto V1 & Recombination crossovers between IAC-112 and Zélia \\
\hline BRS-Angela & CMS-43 \\
\hline Iguatemi I & $\begin{array}{l}\text { Crosses involving the S5 lines Zélia, CMS-42, CMS-43, UEM-J1, and RS-20, with an American genotype and a } \\
\text { material called Catedral }\end{array}$ \\
\hline Iguatemi 2 & $\begin{array}{l}\text { Crosses involving the S5 lines Zélia, IAC-112, CMS-42, CMS-43, UEM-J1, Viçosa, and RS-20 with an American } \\
\text { genotype and a material called Catedral }\end{array}$ \\
\hline Composto V2 & Crossovers between IAC-112, Zélia, and BRS-Angela, with subsequent recombination \\
\hline Composto Barreto & Crossing of five inbred lines extracted from Zélia, with five inbred lines of the local population UEM-J1 \\
\hline Composto Matheus & $\begin{array}{l}\text { Crossing of eight populations of white grains: PR-038, PR-079, RR-046, SC-016, PR-017, BRS-Angela, } \\
\text { SC-002, and PR-009 }\end{array}$ \\
\hline P1 sintético & Crossing of lines drawn from an American hybrid, with the lineages obtained IAC-112 \\
\hline Composto Fracaro & Crossing between hybrid topcrosses BRS-Angela, IAC-112, and Zélia with lines S2 of CMS-43 \\
\hline Composto Aelton & Crossing of five lineages elite S4 of Zélia \\
\hline PR-023 & Obtained from advanced generations of an American hybrid \\
\hline IAC-112 F2 & F2 generation of hybrid IAC-112 \\
\hline Argentina & Genotype originating from Argentina of unknown pedigree \\
\hline UNB-2 & Crossing the population UNB-1 population with popcorn American \\
\hline PA-091 & Advanced generation of American hybrid \\
\hline Viçosa & Crosses between local populations and American hybrids \\
\hline CMS-42 & Cross between 25 yellow grain materials \\
\hline SE-013 & Advanced generation of an American hybrid \\
\hline Laranjeiras do Sul & From Taiwan (Republic of China) \\
\hline UEM-M2 & Unknown pedigree \\
\hline RS-20 & Unknown pedigree \\
\hline
\end{tabular}

\section{Molecular analysis using RAPD markers}

To analyze diversity using RAPD molecular markers, 15 primers with a high degree of polymorphism and strong band intensity were selected, including OPA12, OPA13, OPB01, OPB07, OPB08, OPC01, OPC04, OPC06, OPC07, OPC08, OPC09, OPC10, OPC12, OPC13, and OPC16. To amplify the DNA of various bulk samples, the primers OPA12, OPB01, OPB07, OPB08, OPC04, OPC06, and OPC16 were used at a concentration of $0.2 \mu \mathrm{M}$ and the primers OPA13, OPC01, OPC07, OPC08, OPC09, OPC10, OPC12, and OPC13 were used at a concentration of $0.27 \mu \mathrm{M}$. These conditions were necessary to improve the clarity of the amplified fragments. The patterns and quality of the DNA amplification for these genotypes, following standardization, are shown in Figure 1, which shows the DNA fragments amplified using primer OPC09.

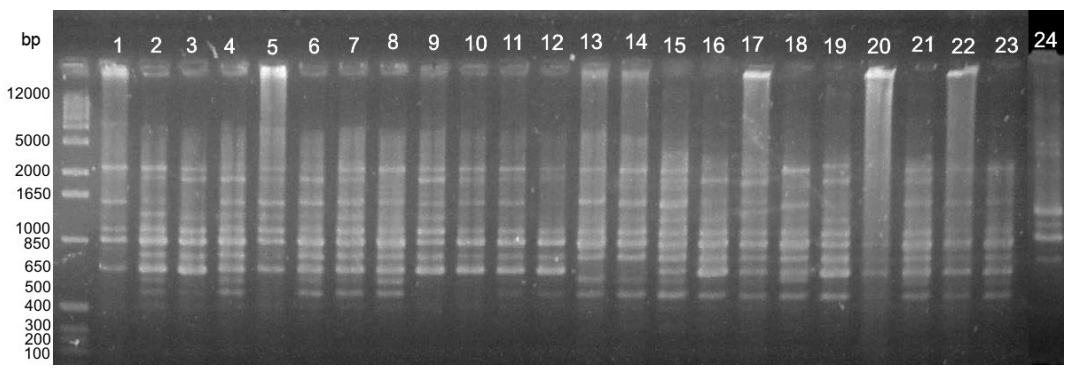

Figure 1. Agarose gel used to separate DNA fragments. Samples 1 to 24 were amplified with the OPC-09 primer to $0.8 \mu \mathrm{L}$ and the enzyme Platinum Taq DNA Polymerase. The well before sample 1 corresponds to the 1-kb DNA ladder. 
The amplification reactions were performed in a Techne TC-512 thermocycler (Bibby Scientific, Ltd., Staffordshire, UK) and prepared in 0.2-mL microtubes. The reactions were standardized to a final reaction volume of $20 \mu \mathrm{L}$ and included $1 \mathrm{U}$ TaqDNA polymerase, 2.0 $\mu \mathrm{L} 10 \mathrm{X}$ reaction buffer (Invitrogen, Carlsbad, CA, USA), $0.1 \mu \mathrm{M}$ of each dNTP, $2.0 \mathrm{mM}$ $\mathrm{MgCl}_{2}, 0.2$ or $0.27 \mu \mathrm{M}$ primer, $20 \mathrm{ng}$ genomic DNA, and autoclaved milli-Q water. The following program was used: $96^{\circ} \mathrm{C}$ for $5 \mathrm{~min}$, followed by 45 amplification cycles at $94^{\circ} \mathrm{C}$ for 1 $\min , 35^{\circ} \mathrm{C}$ for $1 \mathrm{~min}$, and $72^{\circ} \mathrm{C}$ for $2 \mathrm{~min}$. A final 7 -min extension step was performed at $72^{\circ} \mathrm{C}$.

The amplification products were separated by $1.7 \%$ agarose gel electrophoresis in 0.5X TBE buffer, $\mathrm{pH} 8.0$ (0.045 M Tris-borate, 0.001 M EDTA). Electrophoresis was conducted for approximately $5 \mathrm{~h}$ at $60 \mathrm{~V}$. The gels were stained in $0.5 \mu \mathrm{g} / \mathrm{mL}$ ethidium bromide and imaged using a High-Performance Ultraviolet Transilluminator (EDAS 290) with the program Kodak 1D 3.5. To determine the lengths of the amplified fragments, 1-kb DNA Ladder (Invitrogen) molecular weight marker was used.

\section{Genetic and statistical analysis}

The data generated using the RAPD primer amplification were converted into numerical code, with the presence of a band assigned as 1 and the absence of a band assigned as 0 , resulting in a binary matrix. To calculate the genetic distances among the 26 cultivars, the complements of the Jaccard, Rogers and Tanimoto, and Dice similarity coefficients were calculated using the program GENES (Cruz, 2013).

Based on each of the distance measures, a matrix of $\mathrm{D}_{\mathrm{ij}}$ values (dissimilarity matrix) was constructed and a dendrogram was generated using the unweighted pair-group method with arithmetic average method in the program Mega, version 5 (Kumar et al., 2009), to visually represent the genetic distances among genotypes in a more simplified manner.

\section{RESULTS AND DISCUSSION}

RAPD analysis of 26 popcorn cultivar samples using the 15 selected primers yielded a total of 157 amplified fragments. Of these, 65 were monomorphic (41.4\%) and 92 were polymorphic $(58.6 \%)$, generating a mean of 6.13 polymorphic bands per primer. The primer that yielded the highest number of bands and most polymorphisms was OPA-12, which generated 17 bands, 13 of which were polymorphic (76.47\%). Moreover, the primer with the fewest polymorphisms was OPC-01, which generated 11 bands, only 3 of which were polymorphic (27.27\%) (Table 2).

The level of polymorphism detected in the samples analyzed was lower than the values (74.3, 62, 89.24, and 82.54\%) reported by Vilela et al. (2008), Munhoz et al. (2009), Leal et al. (2010), and Souza et al. (2012), respectively. This lower level of polymorphism can be explained by the fact that several of the genetic samples analyzed in this study shared common genotypes in their pedigree, indicating small genetic distances among these samples. This result was confirmed by comparison with a study by Munhoz et al. (2009), who analyzed many of the same samples included in this study and obtained a mean of 6.75 polymorphic bands per primer, a value that was $9.2 \%$ higher than that observed in this study.

According to the distance matrices generated from the RAPD markers, for all coefficients evaluated, the greatest genetic distance was observed between UNB-2 and PA091. The distance between these 2 cultivars was 0.65 using the Jaccard coefficient, 0.74 using 
the Rogers and Tanimoto coefficient, and 0.48 using the Dice coefficient, indicating that among the genetic material analyzed, these cultivars were more distinct, likely because they do not share common genotypes in their genetic constitutions. The PA-091 genotype is the result of an advanced generation of an American hybrid. In turn, the genotype UNB-2 is an open-pollinated variety that originated from the selection of an indigenous composite from the Luiz de Queiroz College of Agriculture/University of São Paulo. This indigenous composite was donated to the National University of Brasília, giving rise to UNB-1. This genotype was crossed with an American population of popcorn, and selected progenies were then crossed with a population of popcorn with yellow grains that was resistant to Exserohilum turcicum. After 2 cycles of mass selection, a population of resistant plants with high yields and yellow grains was obtained. This population was backcrossed 3 times with the American cultivar, yielding UNB-2.

Table 2. Number of amplicons (NA) and number and frequency of monomorphic (NMF) and polymorphic (NPF) fragments obtained for each primer used to amplify the DNA of different genotypes of popcorn.

\begin{tabular}{|c|c|c|c|c|c|}
\hline Primers & NA & NMF & $(\%)$ & NPF & $(\%)$ \\
\hline OPA12 & 17 & 4 & 23.52 & 13 & 76.47 \\
\hline OPA13 & 8 & 3 & 37.50 & 5 & 62.50 \\
\hline OPB01 & 14 & 6 & 42.85 & 8 & 57.14 \\
\hline OPB07 & 13 & 4 & 30.76 & 9 & 69.23 \\
\hline OPB08 & 7 & 4 & 57.14 & 3 & 42.85 \\
\hline OPC01 & 11 & 8 & 72.72 & 3 & 27.27 \\
\hline OPC04 & 8 & 5 & 62.50 & 3 & 37.50 \\
\hline OPC06 & 6 & 3 & 50.00 & 3 & 50.00 \\
\hline OPC07 & 12 & 3 & 25.00 & 9 & 75.00 \\
\hline OPC08 & 13 & 6 & 46.15 & 7 & 53.84 \\
\hline OPC09 & 10 & 3 & 30.00 & 7 & 70.00 \\
\hline OPC 10 & 13 & 6 & 46.15 & 7 & 53.84 \\
\hline OPC 12 & 8 & 4 & 50.00 & 4 & 50.00 \\
\hline OPC13 & 11 & 3 & 27.27 & 8 & 72.72 \\
\hline OPC 16 & 6 & 3 & 50.00 & 3 & 50.00 \\
\hline Total & 157 & 65 & 41.40 & 92 & 58.59 \\
\hline
\end{tabular}

Regarding the smallest genetic distance between 2 genotypes, the results using the 3 coefficients were not in agreement. When using the Dice coefficient, the smallest distance (0.12) was calculated between PR-023 and IAC-125, while using the Jaccard coefficient, the smallest genetic distance (0.21) was observed between IAC-112 and BRS-Angela. Finally, using the Rogers and Tanimoto coefficient, the smallest genetic distance $(0.33)$ was observed between BRS-Ângela and Composto V2. The genotype PR-023 is an open-pollinated population obtained from advanced generations of an American hybrid of unknown pedigree. The genotype IAC-125 is a topcross hybrid from the Agronomic Institute of Campinas. The composite Matheus originated from the crossing of 8 populations with white grains (PR-038, PR079, RR-046, SC-016, PR-017, Angela, SC-002, and PR-009). Except for BRS-Angela, all cultivars sampled were advanced generations of American hybrids. The composite Fracaro was originated by crossing topcross hybrids between Angela, IAC-112, and Zélia with the S2 lines derived from CMS-43.

For cluster analysis considering the Dice dissimilarity coefficient and a cutoff point of 0.25 (point of abrupt change in group formation), based on the generated dendrogram, 4 major groups were identified. Groups I, II, and III were formed by variety UNB-2, the Argentina 
genotype, and variety PA-091, respectively, while group IV was composed of the remaining genetic samples analyzed in this study. Upon subdividing group IV, a group was formed that included the genotypes with the smallest genetic distances together, including C. Fracaro, SE-013, BRS-Ângela, C. V1, C. Matheus, Zélia, UEM-M2, Jade, Iguatemi-2, P1 sintético, PR-023, IAC-125, Iguatemi-1, and Viçosa. Another subdivision of group IV was composed of a group of 8 genotypes with intermediate genetic distances (C. V2, IAC-112, Laranjeiras do Sul, C. Aelton, C. Barreto, Chile, RS-20, and CMS-42) and the IAC-112-F2 population, which was the most divergent cultivar in this group (Figure 2).

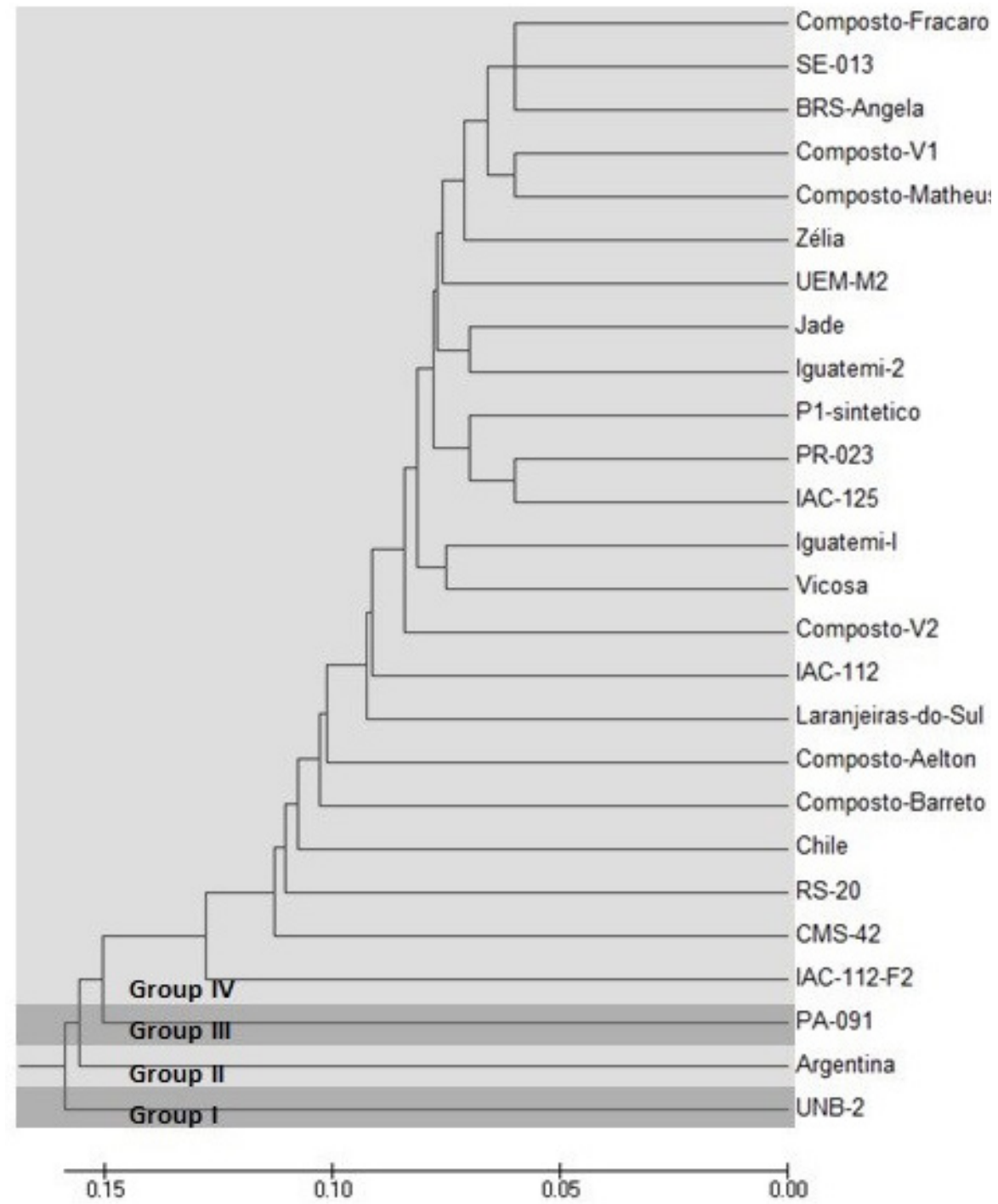

Figure 2. Dendrogram of genetic dissimilarity to 26 popcorn genotypes analyzed, based on the Dice coefficient determined by clustering UPGMA method (cophenetic coefficient of correlation $=0.90$ ). 
Upon analyzing the cluster-generated using the matrix obtained using the Jaccard dissimilarity coefficient, the grouping pattern was very similar to that obtained using the Dice coefficient, with the formation of 4 major groups and 4 subgroups within group IV (Figure 3 ). Differences were observed in the composition of the group with the smallest genetic distances, with the inclusion of genotype IAC-112, which, using this method, grouped more closely to genotype IAC-125. With the inclusion of IAC-112, the genotypes with the smallest genetic distances were separated into 2 groups, of which group IV-D-1 was formed by the genotypes C. Matheus, C. Fracaro, C. V1, Zélia, UEM-M2, SE-013, BRS-Angela, and IAC-112, while group IV-D-2 was formed by the genotypes PR-023, IAC-125, Jade, Iguatemi-2, and P1 sintético. Within group IV, the genotype IAC-112-F2 was also the most dissimilar, indicating that segregation of the F2 generation generated individuals that were genetically distinct from the F1 plants from which they originated. The order of the most divergent cultivars was the same as that described using the Dice coefficient (Figure 3).

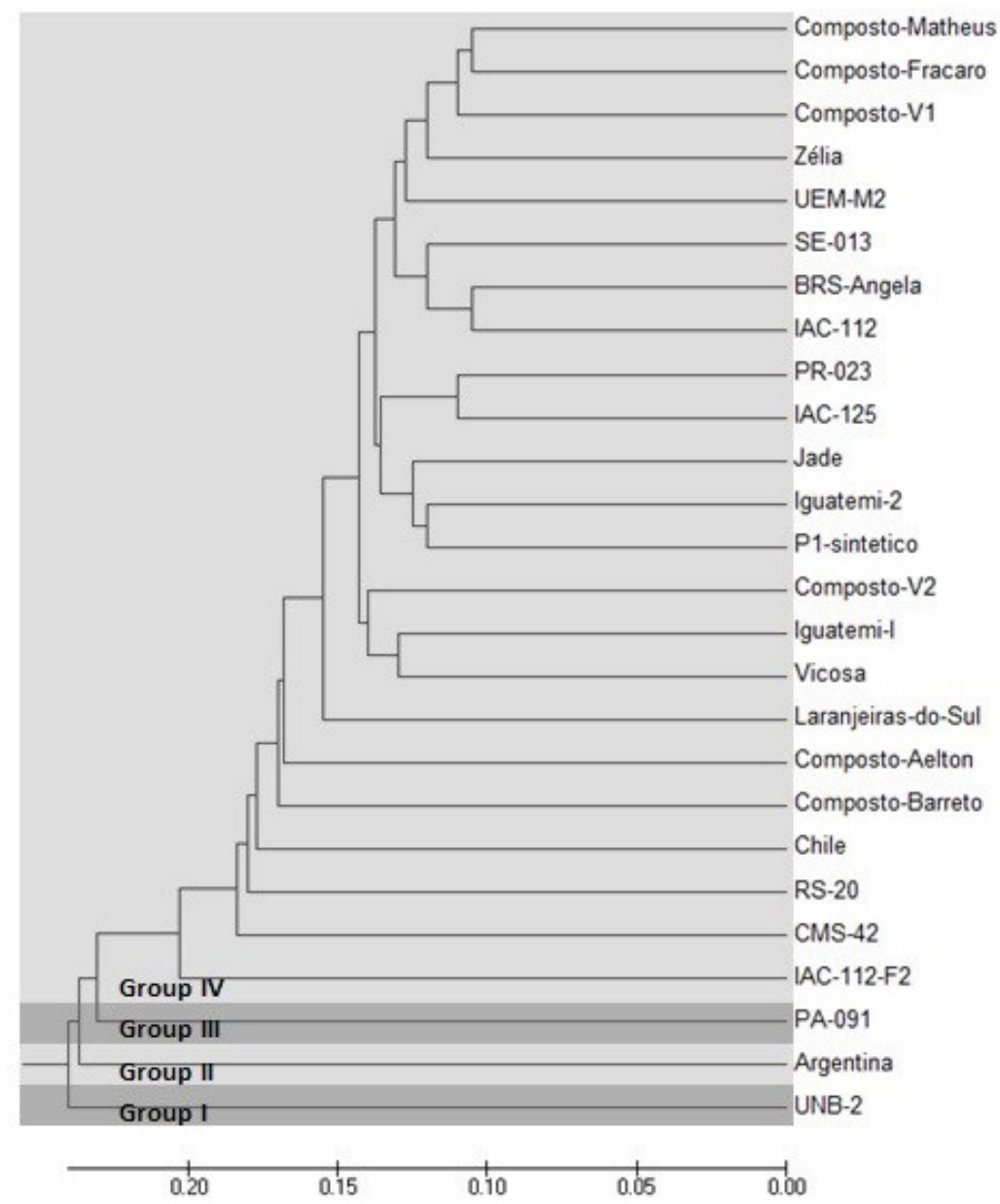

Figure 3. Dendrogram of genetic dissimilarity for the 26 popcorn genotypes analyzed based on Jaccard coefficient, determined by the UPGMA clustering method (coefficient of cophenetic correlation $=0.91$ ). 
Using the Rogers and Tanimoto coefficient to estimate genetic distance, there was a slightly different grouping pattern compared to the patterns observed for the Dice and Jaccard coefficients. Using a cutoff point in the abrupt change region of a mean distance of $0.28,3$ main groups were formed, of which group I was formed by genotype UNB-2, group II was formed by the Argentina and PA-091 genotypes, and group III consisted of the other genotypes analyzed in this study, which was equivalent to group IV in the groupings described above. Similar to the results observed using the Jaccard and Dice coefficients, genotype IAC-112-F2 was the most divergent within group III. Compared to the results for the other coefficients, there was also no difference in the formation of subgroups with smaller distances within group III. In this case, the subgroup with the smallest distance included 15 genotypes, with the inclusion of genotypes C. V2, Iguatemi-1, and Viçosa. Within this subgroup, these 15 genotypes were clustered into 3 smaller groups. The first subgroup was formed by the genotypes C. Matheus, C. Fracaro, C. V1, Zélia, SE-013, BRS-Angela, and C. V2; the second subgroup was formed by genotypes Iguatemi 1 and Viçosa; and the third subgroup was formed by the genotypes PR-023, IAC-125, UEM-M2, Jade, Iguatemi 2, and P1 sintético. The remaining genotypes had intermediate genetic distances within group III (Figure 4).

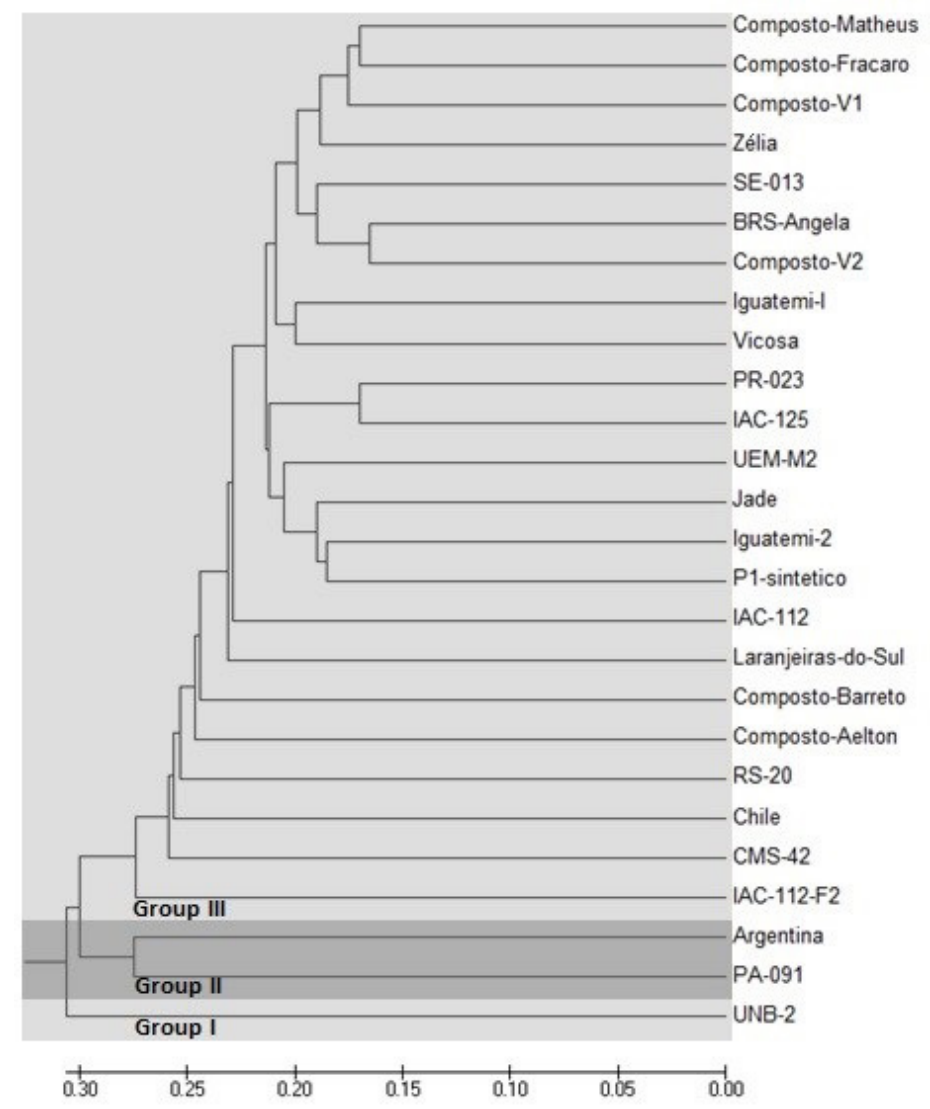

Figure 4. Dendrogram of genetic dissimilarity for the 26 popcorn genotypes analyzed, based on the coefficient of Rogers and Tanimotto determined by UPGMA clustering method (cophenetic correlation coefficient $=0.89$ ). 
The comparison of the 3 dissimilarity coefficients analyzed in this study revealed no major differences in their grouping patterns because there was a high level of agreement in the determination of genotypes with large, small, and intermediate genetic distances. The largest genetic distances were observed when the Rogers and Tanimoto dissimilarity coefficient (0.74) was analyzed, followed by the Jaccard coefficient (0.65) and the Dice coefficient (0.48). In regards to the intermediate distances, values of $0.51,0.36$, and 0.22 were observed for the Rogers and Tanimoto, Jaccard, and Dice coefficients, respectively. The 3 coefficients also generated similar estimates for the cophenetic correlation coefficient, a parameter that measures the consistency of the grouping pattern in relation to the genetic distance matrix. The cophenetic correlation coefficient estimates showed high magnitudes, with values of $0.91,90.0$, and 0.89 for the Dice, Jaccard, and Rogers and Tanimoto coefficients, respectively (Figures 2 to 4). Similarly to the observations by da Silva Meyer et al. (2004), correlations between the matrices obtained using the 3 coefficients in the present study also had high magnitudes and were positive and highly significant based on the Mantel test at the $1 \%$ probability level (Table 3 ), demonstrating a strong association between the results.

Table 3. Correlation between genetic distance matrices obtained by the coefficients of Jaccard, Dice, and Rogers
and Tanimotto.
\begin{tabular}{lccc}
\hline Matrices & Jaccard & Dice & Rogers and Tanimotto \\
\hline Jaccard & - & - & \\
Dice & $0.9969^{* *}$ & $0.9792^{* *}$ & - \\
Rogers and Tanimotto & $0.9844^{* *}$ &
\end{tabular}

**Significant at $1 \%$ probability by the Mantel test with 1000 permutations.

Our results showed that the 3 coefficients generated consistent and concordant results in the analysis of genetic distances among popcorn genotypes based on dominant molecular markers, but the Jaccard coefficient may be slightly better in estimating genetic distance values. Leal et al. (2010) compared the efficiency of RAPD and simple sequence repeat markers in studying the genetic diversity of popcorn and found that both markers produced identical genetic divergence values, indicating that RAPD markers were as effective as simple sequence repeat markers for analyzing genetic diversity, while lowering costs and simplifying application of the technique. The authors also noted that RAPD markers are an appropriate strategy for monitoring and guiding improvement programs for popcorn.

The observed genetic distances for popcorn in this study indicate which crossings will allow for the generation segregating populations with a high degree of genetic variability, allowing for the selection of superior genotypes. Furthermore, the results of molecular analyses using RAPD markers will enable definition and allocation of available popcorn germplasms within groups with different heterotic patterns, thus increasing the chances of achieving significant genetic progress in crop improvement programs. In this context, Lanza et al. (1997) reported that RAPD markers are efficient for establishing consistent heterotic groups among corn genotypes. Other studies focusing on corn cultivation have also reported success in defining heterotic groups based on RAPD markers (Parentoni et al., 2001; Bruel et al., 2006; Souza et al., 2012). However, for popcorn, studies in this area remain limited, and additional studies are needed for a better understanding of the pedigree of the germplasm used in breeding programs, as well as knowledge of the genetic and genomic relationships for the consistent establishment of heterotic groups. 


\section{ACKNOWLEDGMENTS}

We thank the National Council for Scientific and Technological Development (Conselho Nacional de Desenvolvimento Científico e Tecnológico - CNPq) for granting a scholarship F.S. Resh.

\section{REFERENCES}

Bordallo PN, Pereira MG, do Amaral AT Jr and Gabriel APC (2005). Análise dialélica de genótipos de milho doce e comum para caracteres agronômicos e proteína total. Hortic. Bras. 23: 123-127.

Borém A and Miranda GV (2013). Melhoramento de plantas. Editora UFV, Viçosa.

Bruel DC, Carpentieri-Pípolo V, Gerage AC, Fonseca Júnior NS, et al. (2006). Genetic distance estimated by RAPD markers and its relationship with hybrid performance in maize. Pesq. Agropec. Bras. 41: 1491-1498.

Carvalho VP, Ruas CF, Ferreira JM, Moreira RMP, et al. (2004). Genetic diversity among maize (Zea mays L.) landraces assessed by RAPD markers. Genet. Mol. Biol. 27: 228-236.

Cruz CD (2013). GENES - a software package for analysis in experimental statistics and quantitative genetics. Acta Sci. Agron. 35: 271-276.

da Silva Meyer A, Garcia AAF, de Souza AP and de Souza CL Jr (2004). Comparison of similarity coefficients used for cluster analysis with dominant markers in maize (Zea mays L.). Genet. Mol. Biol. 27: 83-91.

Freitas SP Jr, do Amaral AT Jr, Rangel RM, and Viana (2009). Predição de ganhos genéticos na população de milho pipoca UNB-2U sob seleção recorrente utilizando-se diferentes índices de seleção. Semin. Cienc. Agrar. 30: 803-814.

Galvão JCC, Sawazaki E and Miranda GV (2000). Comportamento de híbridos de milho pipoca em Coimbra, Minas Gerais. Rev. Ceres 47: 201-218.

Hallauer AR, Carena MJ and Miranda Filho JB (2010). Quantitative genetics in maize breeding. 3rd edn. Springer-Verlag, Berlin.

Hoisington D, Khairallah M and González-Léon D (1994). Laboratory protocols: CIMMYT Applied Molecular Genetics Laboratory. 2nd edn. CIMMYT, Texacoco.

Kumar S, Nei M, Dudley J and Tamura K (2009). MEGA: A biologist-centric software for evolutionary analysis of DNA and protein sequences. Brief. Bioinform. 9: 299-306.

Lanza LLB, de Souza CL Jr, Ottoboni LMM, Vieira MLC, et al. (1997). Genetic distance of inbred lines and prediction of maize single-cross performance using RAPD markers. Theor. Appl. Genet. 94: 1023-1030.

Leal AA, Mangolin CA, do Amaral AT Jr, Gonçalves LS, et al. (2010). Efficiency of RAPD versus SSR markers for determining genetic diversity among popcorn lines. Genet. Mol. Res. 9: 9-18.

Moeller DA and Schaal BA (1999). Genetics relationships among Native American maize accessions of the Great Plains assessed by RAPDs. Theor. Appl. Genet. 99: 1061-1067.

Munhoz REF, Prioli AJ, do Amaral AT Jr, Scapim CA, et al. (2009). Genetic distances between popcorn populations based on molecular markers and correlations with heterosis estimates made by diallel analysis of hybrids. Genet. Mol. Res. 8: 951-962.

Parentoni SN, Magalhães JV, Pacheco CAP, Santos MX, et al. (2001). Heterotic groups based on yield-specific combining ability data and phylogenetic relationship determined by RAPD markers for 28 tropical maize open pollinated varieties. Euphytica 121: 197-208.

Pena GF, do Amaral AT Jr, Gonçalves LSA, Candido LS, et al. (2012). Stability and adaptability of popcorn genotypes in the State of Rio de Janeiro, Brazil. Genet. Mol. Res. 11: 3042-3050.

Pereira MG and do Amaral AT Jr (2001). Estimation of genetic components in popcorn based on the nested design. Crop Breed. Appl. Biotechnol. 1: 3-1.

Pípolo CV, Takahashi HW, Endo RM, Petek MR, et al. (2002). Correlações entre caracteres quantitativos em milho pipoca. Hortic. Bras. 20: 551-554.

Rangel RM, Amaral AT Jr, Scapim CA, Freitas SP Jr, et al. (2008). Genetics and parameters in parents and hybrids of circulant diallel in popcorn. Genet. Mol. Res. 7: 1020-1030.

Ribeiro RM, do Amaral AT Jr, Gonçalves LSA, Candido LS, et al. (2012). Genetic progress in the UNB-2U population of popcorn under recurrent selection in Rio de Janeiro. Genet. Mol. Res. 11: 1417-1423.

Sakiyama NS, Ramos HCC, Caixeta ET and Pereira MG (2014). Plant breeding with marker-assisted selection in Brazil. Crop Breed. Appl. Biotechnol. 14: 54-60.

Santos LM, Braccini AL, Scapim CA, Pinto RJB, et al. (2012). Combining ability of popcorn lines for seed quality and 
agronomic traits. Euphytica 185: 337-347.

Sawazaki E (2001). A cultura do milho pipoca no Brasil. Agronômico 53: 11-13.

Scapim CA, Pacheco CAP, Tonet A, Braccini AL, et al. (2002). Análise dialélica e heterose de populações de milho pipoca. Bragantia 61: 219-230.

Silva TRC, do Amaral AT Jr, Gonçalves LSA, Candido LS, et al. (2013). Agronomic performance of popcorn genotypes in Northern and Northwestern Rio de Janeiro State. Acta Sci. Agron. 35: 57-63.

Souza SGH, Carpentieri-Pípolo V, Garbúglio DD, Fonseca Júnior NS, et al. (2012). Genetic distance estimated by RAPD markers and performance of topcross hybrids in popcorn. Am. J. Plant Sci. 3: 1666-1673.

Thormann CE, Ferreira ME, Camargo LE, Tivang JG, et al. (1994). Comparison of RFLP and RAPD markers to estimate genetic relationships within and among cruciferous species. Theor. Appl. Genet. 88: 973-980.

Vilela FO, do Amaral AT Jr, Pereira MG, Scapim CA, et al. (2008). Effect of recurrent selection on the genetic variability of the UNB-2U popcorn population using RAPD markers. Acta Sci. Agron. 1: 25-30.

Vitorazzi C, do Amaral AT Jr, Gonçalves LSA, Candido LS, et al. (2013). Selecting pre-cultivars of popcorn maize based on nonparametric indices. Rev. Cienc. Agron. 44: 356-362.

Welsh J and McClelland M (1990). Fingerprinting genomes using PCR with arbitrarily primers. Nucleic Acids Res. 18: 7213-7218.

Williams JK, Kubelik AR, Livak KG, Rafalki JA, et al. (1990). DNA polymorphism amplified by arbitrary primers are useful as genetic markers. Nucleic Acids Res. 18: 6531-6535. 